\section{INTERNATIONAL CONFERENCE ON MATHEMATICAL INEQUALITIES AND NONLINEAR FUNCTIONAL ANALYSIS WITH APPLICATIONS}

South Korea is one of the Asian tigers well known for the development of different technologies, from electronic to aircraft technology. It is very surprising to notice that they manufacture all the stuff for their living. Investing in science is a consequence and an inducement for further progress. Thanks to the Faculty of Traffic and Transport Sciences, I had an opportunity to participate at the Conference in Jinju, from July $25^{\text {th }}$ to July $29^{\text {th }}$.

The Gyeongsang National University is located in the campus in Jinju, a town nearby the South Sea coast. The campus of GNU is impressive, consisting of 12 colleges, six graduate schools, 20 divisions (54 majors), one department group (2 departments) and 33 departments with 3,254 new students enrolled per year. The Conference was sponsored by the Research Institute of Natural Sciences at GNU, Jeju National University, The Institute of Basic Sciences from Kyungman University, the Journal of Inequalities and Applications Springer and the University of Zagreb. The Organizing Committee consisted of Yeol Je Cho from GNU, Jong Kyu Kim from Kyungnam University, Young Oh Yang from Jeju University and Josip Pečarić from the University of Zagreb.

In one week of intensive schedule, over 150 invited speakers gave their presentations and discussed the recent topics in integral inequalities, inequalities for differential equations, polynomials, refinements for classic inequalities, functional equations and applications, geometric means, fixed point theory, variational inequality and complementarity problem theory, nonlinear ergodic theory, equilibrium problems, optimization problems, differential and integral equations and dynamic system theory. The participants were providing and receiving new ideas and results on the above topics, collaborating with colleagues from many countries and encouraging young mathematicians to study mathematical inequalities and nonlinear functional analyses. The presentations were organized through five sessions.

Regarding Plenary Talks I was impressed by the talk of Prof. Ravi P. Agarwal from Texas A\&M University who presented Lidstone and Complementary Lidstone Polynomials and Interpolation. Prof. Mohammad Sal Moslehian from the Ferdowsi University of Mashad, Iran, presented the Heinz Inequality and its Refinements, while Zsolt Pales from the University of Debrecen offered some open problems from investigation of the means.

My journey started with missing the flight, so it begun as a real adventure. Fortunately, the missing was bypassed with an efficient intervention and I reached the desired destination. During the Conference we visited Expo in Yeosu gaining impressive experience and then we took a drop of the Korean history in Sacheon, the town on the seaside of South Sea.

Unfortunately, the Korean people have no habit of swimming, so I have no wet experiences from that sea so very far away.

Božidar Ivanković, Ph.D. Faculty of Transport and Traffic Sciences, Zagreb, Croatia 